\title{
Streamrate stagnation-point flow of a nanofluid on a stationary cylinder
}

\author{
Vahid Amerian ${ }^{1}$, Hamid Mohammadiun ${ }^{2} *$, Mohammad Mohammadiun ${ }^{2}$, Iman Khazaee $^{3}$ \\ ${ }^{1}$ Graduate Student, Department of mechanical engineering, Shahrood University, Shahrood, Iran \\ ${ }^{2}$ Assistant Professor, Department of mechanical engineering, Shahrood branch, Islamic Azad University, Shahrood, Iran \\ ${ }^{3}$ Assistant Professor, Faculty of Mechanical and Energy Engineering, ShahidBeheshti University, A.C., Tehran, Iran \\ *Corresponding author E-mail:hmohammadiun@yahoo.com
}

Copyright $\odot$ 2015VahidAmerian et al. This is an open access article distributed under the Creative Commons Attribution License, which permits unrestricted use, distribution, and reproduction in any medium, provided the original work is properly cited.

\begin{abstract}
The steady-state, viscous flow of Nanofluid in the vicinity of an axisymmetric stagnation point of a stationary cylinder is investigated. The impinging free-stream is steady and with a constant strain rate $\bar{k}$. Exact solution of the NavierStokes equations is derived in this problem. A reduction of these equations is obtained by use of appropriate transformations introduced in this research. The general self-similar solution is obtained when the wall temperature of the cylinder is constant. All the solutions above are presented for Reynolds numbers ranging from 0.1 to 1000 and selected values of particle. For all Reynolds numbers, as the particle fraction increases, the depth of diffusion of the fluid velocity field in radial direction, the depth of the diffusion of the fluid velocity field in $z$-direction, shear-stresses and pressure function decreases.
\end{abstract}

\section{Nomenclature}

$\begin{array}{ll}\rho_{n} & \text { Density of the nanofluid } \\ \phi_{v} & \text { Particle fraction } \\ \rho_{f} & \text { Density of the base fluid } \\ \rho_{p} & \text { Density of the particles } \\ d_{f} & \text { Equivalent diameter of a base fluid molecule } \\ d_{p} & \text { Equivalent diameter of a particle molecule } \\ \mu_{n} & \text { Dynamic viscosity of the nanofluid } \\ \mu & \text { Dynamic viscosity of the base fluid } \\ \eta & \text { Similarity variable } \\ \operatorname{Re}_{n} & \text { Reynolds number for nanofluid } \\ \operatorname{Re}_{\bar{k}} & \text { Reynolds number for base fluid } \\ a & \text { free stream strain rate } \\ r, z & \text { Cylinder radius } \\ v & \text { Cylindrical coordinates } \\ u & \text { Kinematic viscosity of base fluid } \\ & \text { Velocity component in radial direction }\end{array}$




$\begin{array}{ll}w & \text { Velocity component in axial direction } \\ \sigma & \text { Shear stress } \\ p & \text { fluid pressure } \\ P & \text { nondimensional pressure } \\ f & \text { Dimensionless function } \\ v_{n} & \text { Kinematic viscosity of nanofluid }\end{array}$

Keywords:Nanofluid; Stagnation-Point Flow; Stationary Cylinder; Self-Similar Solution; Particle Fraction.

\section{Introduction}

Nanofluid, a name conceived by Choi [1] in Argonne National laboratory, are fluids consisting of solid nanoparticles with size smaller than $100 \mathrm{~nm}$ suspended with solid volume fraction typically less than $4 \%$. Nanofluid could enhance heat transfer performance compared to pure liquids. Nanofluids could be used to improve thermal management system in many engineering applications such as transportation, micromechanics and instrument, HVAC system and cooling devices. Recently, many investigators have studied nanofluid convective heat transfer in different geometries both numerically and experimentally (Maiga et al.[2]; Heris et al.[3]; Duangthongsuk and Wongwises[4]; Santra et al.[5]; Nguyen et al.[6]). The natural convection boundary layer flow has been discussed analytically by Kuznetsov and Nield[7] .They showed that the model used for the nanofluid incorporates the effects of Brownian motion and thermophoresis. In another research Nield and Kuznetsov[8] have examined the thermal instability in a porous boundary layer saturated by a nanofluid. More recently, Khan and Pop[9] have examined the boundary layer flow of a nanofluid past a stretching surface.

The task of finding exact solutions for Navier-Stokes equations is found to be difficult due to nonlinearity of these equations. However, exact solutions of Navier-Stokes equations are possible for special cases. Hiemenz[10] has obtained an exact solution of the Navier-Stokes equations governing the two-dimensional stagnation point flow on a flat plate. The analogous axisymmetric stagnation- point flow was investigated by Homann[11]. The results of the problem of stagnation flow against a flat plate for asymmetric cases were presented by Howarth[12] and Davey[13]. Wang[14] was first who found exact solution for the problem of axisymmetric stagnation flow on an infinite stationary circular cylinder. Gorla [15-18], in a series of papers, studied the steady and unsteady flows over a circular cylinder in the vicinity of the stagnation-point for the cases of constant axial movement, and the special case of axial harmonic motion of a non-rotating cylinder. This special case is only for small and high values of frequency parameter using perturbation techniques. Recently, Cunning et al. [19] have considered the stagnation flow problem on a rotating circular cylinder with constant angular velocity, including the effects of suction and blowing with constant rate. Takhar et al.[20] have also investigated the unsteady viscous flow in the vicinity of an axisymmetric stagnation point of an infinite circular cylinder when both the cylinder and the free stream velocities vary as a same function of time. Their self-similar solution is only for when both the cylinder and the free-stream velocities vary inversely as a linear function of time and by taking an average value for Reynolds number. Also their semi-similar solutions are for the accelerating and decelerating cases of the cylinder movement, but with the same type of time dependent function as the free-stream velocity and only for Reynolds numbers up to 10 . The most recent works of the same types are the ones by Saleh and Rahimi[21] and Rahimi and Saleh[22, 23], which are exact solution studies of a stagnation-point flow and heat transfer on a circular cylinder with time-dependent axial and rotational movements, as well as studies by Abbasi and Rahimi [24-27], which are exact solutions of stagnation-point flow and heat transfer, but on a flat plate. Some existing compressible flow studies but in the stagnation region of bodies and by using boundary layer equations include the study by Subhashini and Nath[28] as well as Kumari and Nath[29, 30], which are in the stagnation region of a body, and work of Katz[31] as well as Afzal and Ahmad[32], Libby[33], and Gersten et al.[34], which are all general studies in the stagnation region of a body.

In the present analysis, for the first time the steady viscous flow of nanofluid in the vicinity of an axisymmetric stagnation point of a stationary cylinder is considered. Flow is considered in cylindrical coordinates $(r, z)$ with corresponding velocity components $(u, w)$, as Fig. 1. The laminar steady incompressible flow of Nanofluid in the neighborhood of an axisymmetric stagnation-point of a stationary cylinder is considered. An exact solution of the Navier-Stokes equations is obtained. The self-similar solution is reached by introducing the similarity variables. Sample distributions of shear stress and pressure at Reynolds numbers ranging from 0.1 to 1000 are presented for different values of particle fractions. 


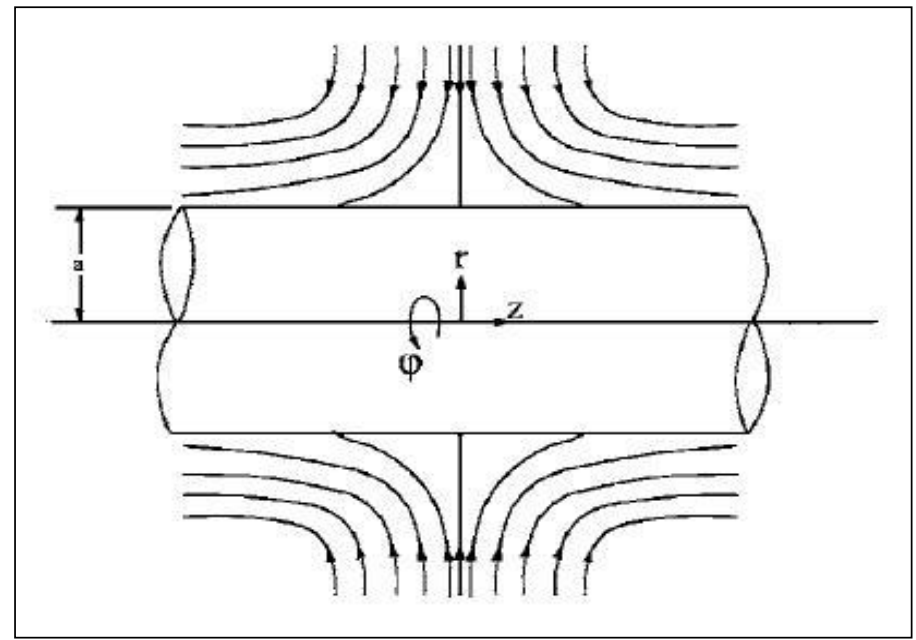

Fig. 1:Schematic Diagram of a Stationary Cylinder

The following picture may best describes how a radial flow can be arranged in order to coat the surface of a cylinder with any kind of protection material. This coating can be considered as protection against erosion or for insulation. The flow into the cylinder is coming from all directions.

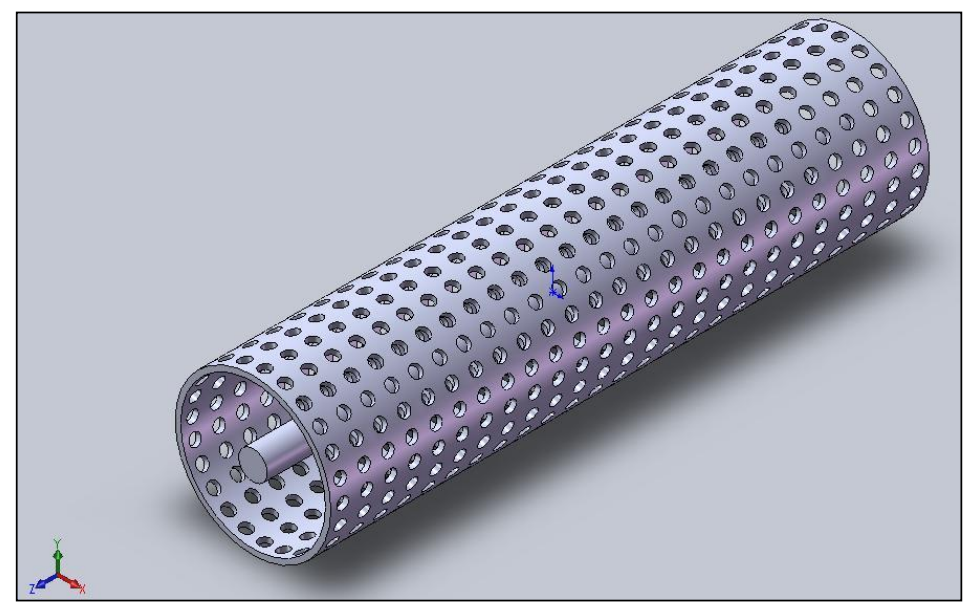

Fig. 2:A Schematic Mechanism of the Radially Impinging Flow Production

Sometimes ceramics and metal powders are used as coating materials in the same manner.

\section{Properties of nanofluid}

The aluminum oxide $\left(\gamma \mathrm{Al}_{2} \mathrm{O}_{3}\right)$ nanoparticles which have been used in this research have the following characteristics:

Density $\rho_{m}=3,880 \mathrm{~kg} / \mathrm{m}^{3}$, mean particle diameter is $47 \mathrm{~nm}$.

\subsection{Density}

We will assume that the density of the aluminum oxide nanoparticles is constant in the entire range of considered temperature. The following relation has been used to compute the nanofluid density:

$\rho_{n}=\left(1-\phi_{v}\right) \rho_{f}+\phi_{v} \rho_{p}$

Where subscripts $\mathrm{n}$, f and $\mathrm{p}$ denote the nanofluid, base fluid and the particles respectively, and $\phi_{v}$ is the particle fraction. 


\subsection{Dynamic viscosity}

The viscosity of the nanofluid can be estimated with the existing relations for the two phase mixture. Drew and Passman introduced Einstein's formula to evaluate the effective viscosity. Fluid is containing a dilute suspension of small rigid spherical particles.

$$
\mu_{n}=\mu_{0}\left(1-2.5 \phi_{v}\right)
$$

This formula is restricted for low volumetric concentration of particle, under $0.05 \%$. Other relations of effective viscosity of the two-phase mixture exist in the literature. Each relation has its own limitation and application. Unfortunately, results reveal that Brinkman's formula underestimates the few experimental data present in literature. The polynomial approximation based on experimental data Nguyen [35] or water- $\gamma \mathrm{Al}_{2} \mathrm{O}_{3}$ nanofluid:

$$
\begin{aligned}
& \mu_{\mathrm{n}}(1 \%)=3.65785 \times 10^{-11} \mathrm{~T}^{4}-4.88267 \times 10^{-8} \mathrm{~T}^{3}+2.45398 \times 10^{-5} \mathrm{~T}^{2}--5.510714 \times \\
& 10^{-3} \mathrm{~T}+0.467545089
\end{aligned}
$$

$\mu_{\mathrm{n}}(2 \%)=3.97752 \times 10^{-11} \mathrm{~T}^{4}-5.30937 \times 10^{-8} \mathrm{~T}^{3}+2.66844 \times 10^{-5} \mathrm{~T}^{2}--5.992306 \times$

$10^{-3} \mathrm{~T}+0.508404721$

$\mu_{\mathrm{n}}(3 \%)=4.5148 \times 10^{-11} \mathrm{~T}^{4}-6.02656 \times 10^{-8} \mathrm{~T}^{3}+3.02889 \times 10^{-5} \mathrm{~T}^{2}--6.801744 \times$

$10^{-3} \mathrm{~T}+0.57707980$

Brinkman proposed the extension Einstein's formula to.

$\mu_{n}=\mu_{0}\left(1-\phi_{v}\right)^{2.5}$

Massimo Corcione proposed empirical correlation for predicting the relative viscosity, [36].

$$
\frac{\mu_{n}}{\mu}=\frac{1}{1-34.87\left(\frac{d_{p}}{d_{f}}\right)^{-0.3} \phi_{v}^{1.03}}
$$

Where $d_{f}$ is the equivalent diameter of a base fluid molecule, given by

$$
d_{f}=0.1\left(\frac{6 M}{N \pi \rho_{f 0}}\right)^{\frac{1}{3}}
$$

In which $\mathrm{M}$ is the molecular weight of the base liquid, $\mathrm{N}$ is the Avogadro number, and $\rho_{f 0}$ is the mass density of the base liquid calculated at temperature $T_{0}=293 \mathrm{k}$.

Finally, the Corcione's formula is used to extract the Navier-stocks equations.

\section{Problem formulation}

Flow is considered in cylindrical coordinates $(\mathrm{r}, \mathrm{z})$ with corresponding velocity components $(\mathrm{u}, \mathrm{w})$, as Fig. 1.

We consider the laminar steady incompressible flow of nanofluid in the neighborhood of an axisymmetric stagnationpoint of a stationary cylinder. The steady Navier-Stokes equations in cylindrical coordinates governing the axisymmetric flow is given by [14-18]: 
Mass Equation:

$$
\frac{\partial}{\partial r}(r u)+r \frac{\partial w}{\partial z}=0
$$

Momentum Equations:

$$
\begin{aligned}
& u \frac{\partial u}{\partial r}+w \frac{\partial u}{\partial z}=-\frac{1}{\rho_{n}} \frac{\partial p}{\partial r}+v_{n}\left(\frac{\partial^{2} u}{\partial r^{2}}+\frac{1}{r} \frac{\partial u}{\partial r}-\frac{u}{r^{2}}+\frac{\partial^{2} u}{\partial z^{2}}\right) \\
& u \frac{\partial w}{\partial r}+w \frac{\partial w}{\partial z}=-\frac{1}{\rho_{n}} \frac{\partial p}{\partial z}+v_{n}\left(\frac{\partial^{2} w}{\partial r^{2}}+\frac{1}{r} \frac{\partial w}{\partial r}+\frac{\partial^{2} w}{\partial z^{2}}\right)
\end{aligned}
$$

The boundary conditions for velocity field are:

$$
\begin{aligned}
& \mathrm{r}=\mathrm{a}: \quad \mathrm{u}=0 \quad, \quad \mathrm{w}=0 \\
& r \rightarrow \infty: u=-\bar{k}\left(r-\frac{a^{2}}{r}\right) \quad, \quad w=2 \bar{k} z
\end{aligned}
$$

In which, (11.a) are no-slip conditions on the cylinder wall and relations (11.b) show that the viscous flow solution approaches, in an analogous manner to the Hiemenz flow, the potential flow solution as $r \rightarrow \infty$.

This can be confirmed by starting from continuity equation as the following:

$$
-\frac{1}{r} \frac{\partial}{\partial r}(r u)=\text { cons } \tan t=2 \bar{k}
$$

A reduction of the Navier-Stokes equations is obtained by the following coordinate separation of the velocity field which is actually modeled by the form of their limits as represented by Equation (11.b):

$$
u=-\bar{k} \frac{a}{\sqrt{\eta+1}} f(\eta), w=2 \bar{k} f^{\prime}(\eta) z, p=\rho_{n} \bar{k}^{2} a^{2} P
$$

Where

$$
\eta=\left(\frac{r}{a}\right)^{2}-1
$$

Is dimensionless radial, variable and prime denotes differentiation with respect to $\eta$. Note that, for the case of base fluid $\left(\phi_{v}=0\right)$, this variable is similar to the one in Wang, Ref. [14], except that it changes from zero to infinity instead of one to infinity. Transformations (13) satisfy (8) automatically and their insertion into (9) - (10) yields an ordinary differential equation in terms of $f(\eta)$, and an expression for the pressure:

$$
\begin{aligned}
& (\eta+1) f^{\prime \prime \prime}+f^{\prime \prime}+\operatorname{Re}_{n}\left[1-\left(f^{\prime}\right)^{2}+f f^{\prime \prime}\right]=0 \\
& P-P_{o}=-\left[\frac{f^{2}(\eta)}{2(\eta+1)}+\frac{1}{\operatorname{Re}} f^{\prime}(\eta)\right]-2\left(\frac{z}{a}\right)^{2}
\end{aligned}
$$

In these equations,

$$
\operatorname{Re}=\frac{\bar{k} a^{2}}{2 v_{f}}
$$




$$
\begin{aligned}
& \operatorname{Re}_{n}=\beta \operatorname{Re} \\
& \beta=\left[1-34.87\left(\frac{d_{p}}{d_{f}}\right)^{-0.3} \phi_{v}{ }^{1.03}\right]\left(1-\phi_{v}+\phi_{v} \frac{\rho_{p}}{\rho_{f}}\right)
\end{aligned}
$$

And $\operatorname{Re}_{n}$ is the Reynolds number for nanofluid and prime indicates differentiation with respect to $\eta$. From conditions (11. A) and (11.b), the boundary conditions for (15) are as follows:

$\eta=0: f=0, f^{\prime}=0$

$\eta \rightarrow \infty: f^{\prime}=1$

Equations (10) and (16) along with boundary conditions (18) have been solved by using the fourth-order Runge-Kutta method of integration along with a shooting method, press et al. [37]. Using this method, the initial values were guessed, and the integration was repeated until the convergence was obtained. In these computations, the grid size was chosen 0.001 , and the truncation error was set at $1 \mathrm{E}-9$.

\section{Shear-stress}

The shear-stress on the surface of the cylinder is obtained from:

$\sigma=\mu_{n}\left[\frac{\partial w}{\partial r}\right]_{r=a}$

Where $\mu_{n}$ is viscosity of the nanofluid. Using definition (13), the shear-stress at the cylinder surface for self-similar solutions becomes.

$$
\sigma=\mu_{n}\left[2 \bar{k} f^{\prime \prime}(0) z\right] \frac{2}{a} \Rightarrow \frac{\sigma a}{4 \mu_{n} \bar{k} z}=f^{\prime \prime}(0)
$$

Results of the shear stress for different values of Reynolds numbers with particle volume fraction held constant, and for different values of particle volume fractions with Reynold's number held constant are presented in the later sections.

\section{Results and discussion}

In this section, the solution of the self-similar equation (15) along with surface shear-stresses for selected values of Reynolds numbers, and particle volume fraction are presented.

Sample profiles of the $f(\eta)$ function against $\eta$ at $\phi_{v}=0.02$ and for selected values of Reynolds numbers are presented in Fig. 3. Since with the increase of Reynold's number of the dynamic inertia forces overcome the viscosities' forces, as expected like the behavior of the base fluid, the depth of diffusion of the momentum increases. So as the Reynolds number increases, the depth of diffusion of the fluid velocity field in radial direction increases, too. 


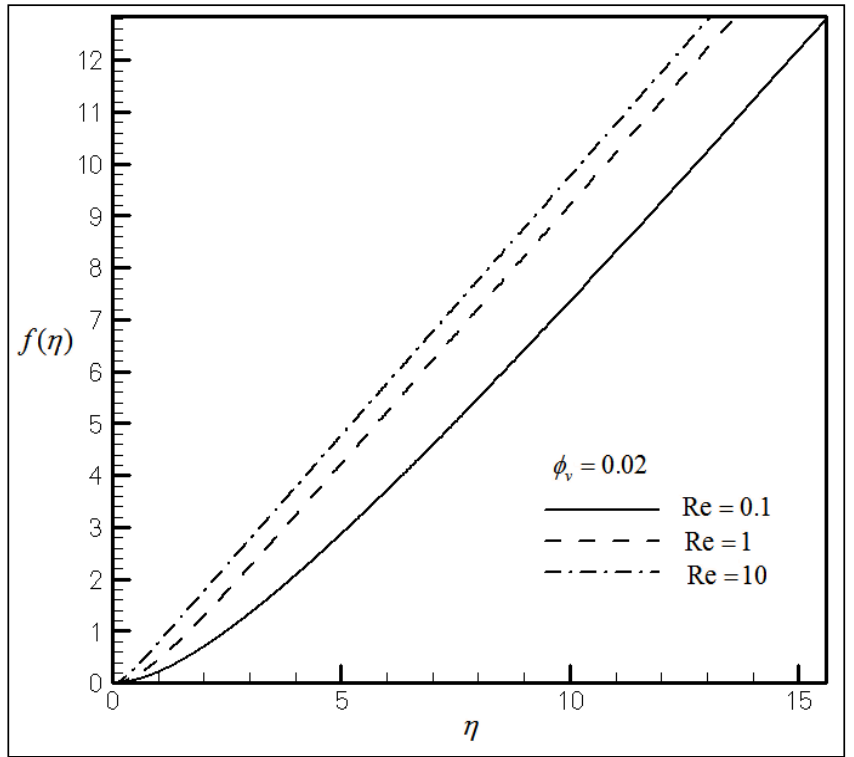

Fig. 3: Variation of $f$ in Terms of $\eta$ at $\phi_{v}=0.02$ for Different Values of Reynolds Numbers

Effect of variation of particle Volume fraction factor on $f(\eta)$ function against $\eta$ and selected value of Reynolds number $\operatorname{Re}=1$ is shown in Fig. 4. Since any increase of $\phi_{v}$ leads to an increase in dynamic viscosity, the resistance of the viscos forces against the dynamic inertia forces increases. It is interesting to note that as $\phi_{v}$ increases the depth of diffusion of the fluid velocity field in radial direction decreases. So, for all the Reynolds numbers, the base fluid case produces the highest value of radial velocity and as particle Volume fraction increases, this quantity decreases accordingly. It can be shown that the trend of above variations are the same for $\operatorname{Re}=10,100$ and 1000 as seen in Fig. 5, 6 and 7.

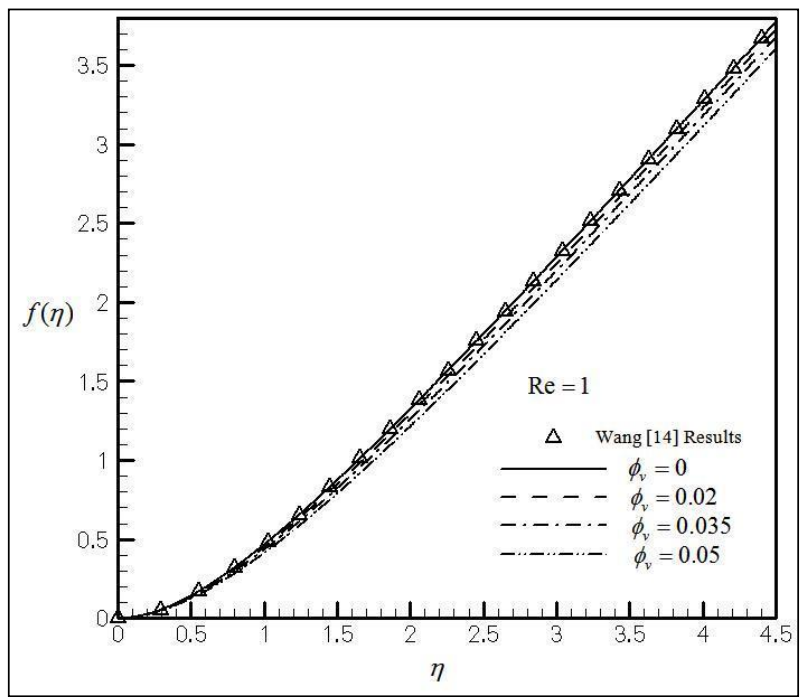

Fig. 4: Variation of $f$ in Terms of $\eta$ at $\operatorname{Re}=1.0$ for Different Values of Particle Volume Fraction 


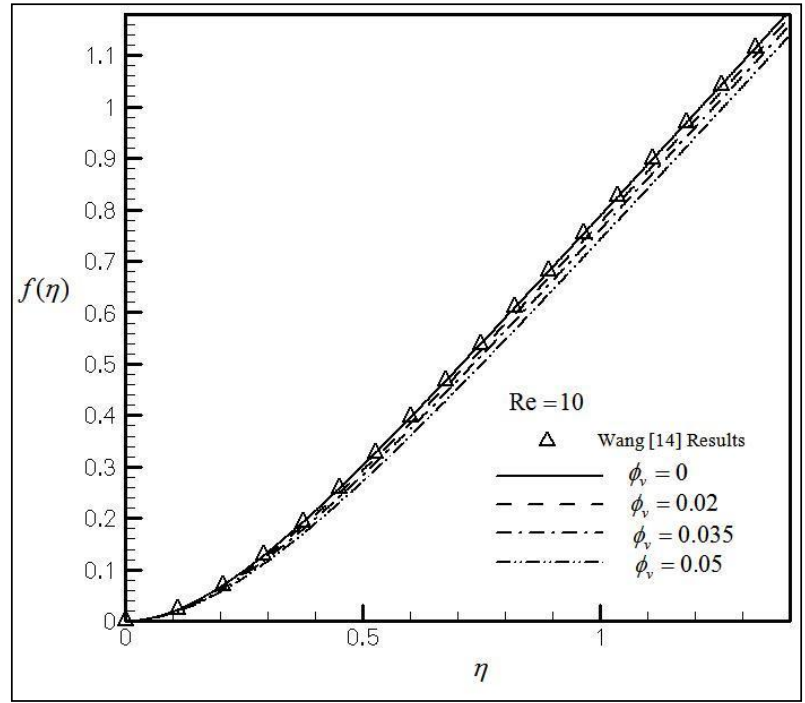

Fig. 5:Variation of $f$ in Terms of $\eta$ At $\operatorname{Re}=10$ and for Different Values of Particle Volume Fraction

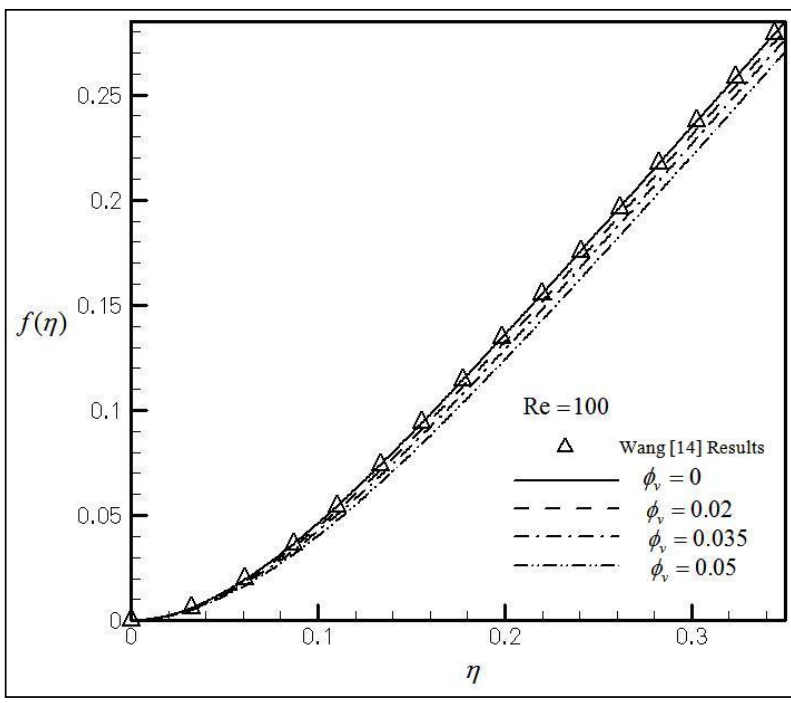

Fig. 6:Variation of $f$ in Terms of $\eta$ at $\mathrm{Re}=100$ and for Different Values of Particle Volume Fraction

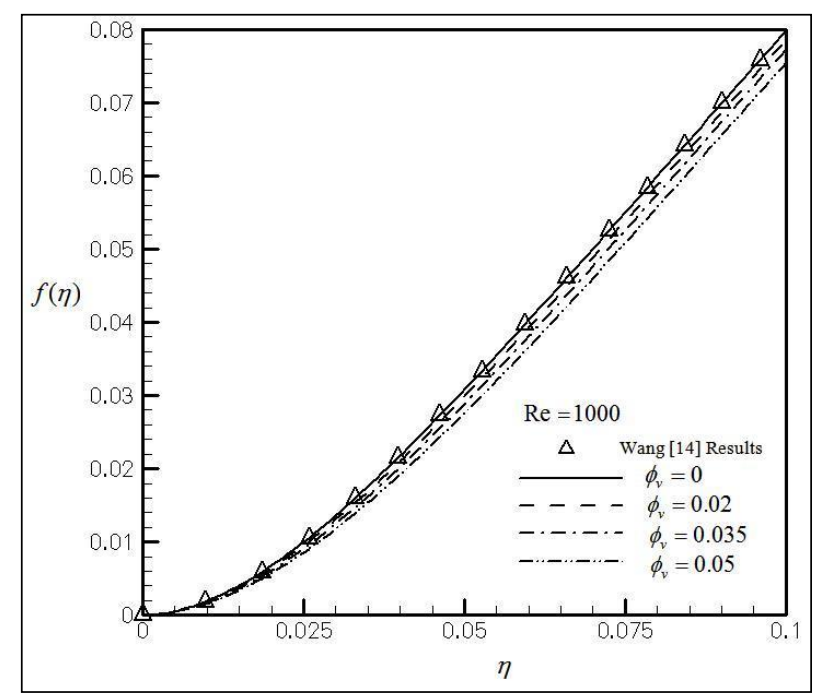

Fig. 7: Variation of $f$ in Terms of $\eta$ at $\mathrm{Re}=1000$ and for Different Values of Particle Volume Fraction

Sample profiles of the $f^{\prime}(\eta)$ function against $\eta$ for $\phi_{v}=0.02$, and for selected values of Reynolds numbers are shown in Fig. 8. Again as Reynold's number increases, the depth of diffusion of the fluid velocity field in $z$ - direction increases, too.

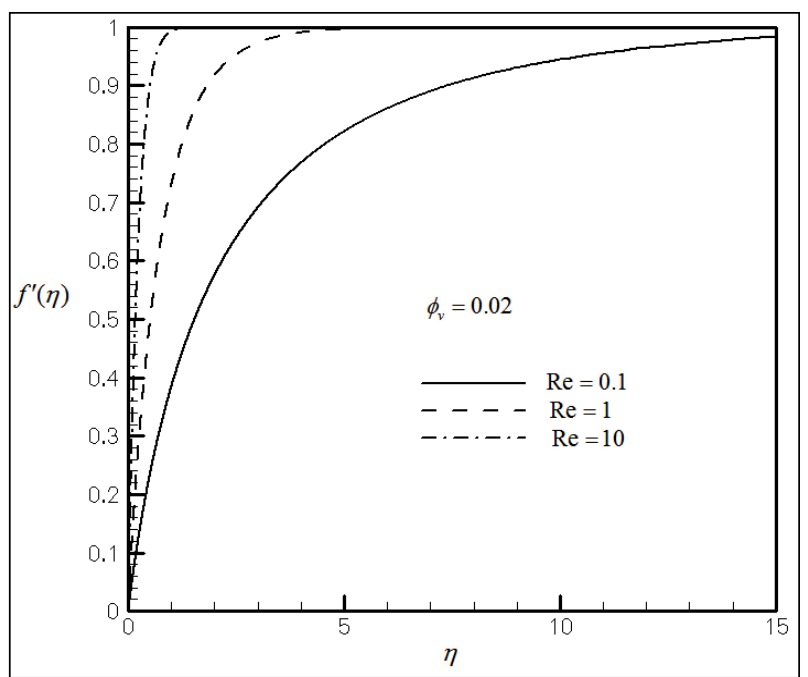

Fig. 8: Variation of $f^{\prime}$ in Terms of $\eta$ at $\phi_{v}=0.02$ and for Different Values of Reynolds Numbers 
Effects of variations of particle Volume fraction factor on $f^{\prime}(\eta)$ function against $\eta$ for selected value of Reynolds number $\mathrm{Re}=0.1$ are shown in Fig.9. It is interesting to note that as $\phi_{v}$ increases the depth of the diffusion of the fluid velocity field in $z$-direction also decreases. Again, the base fluid case $\left(\phi_{v}=0\right)$ produces the highest value of velocity in $z$-direction and as particle Volume fraction factor increases, this quantity decreases accordingly. It can be shown that the trend of above variations are the same for $\operatorname{Re}=1,10,100$ and 1000 .

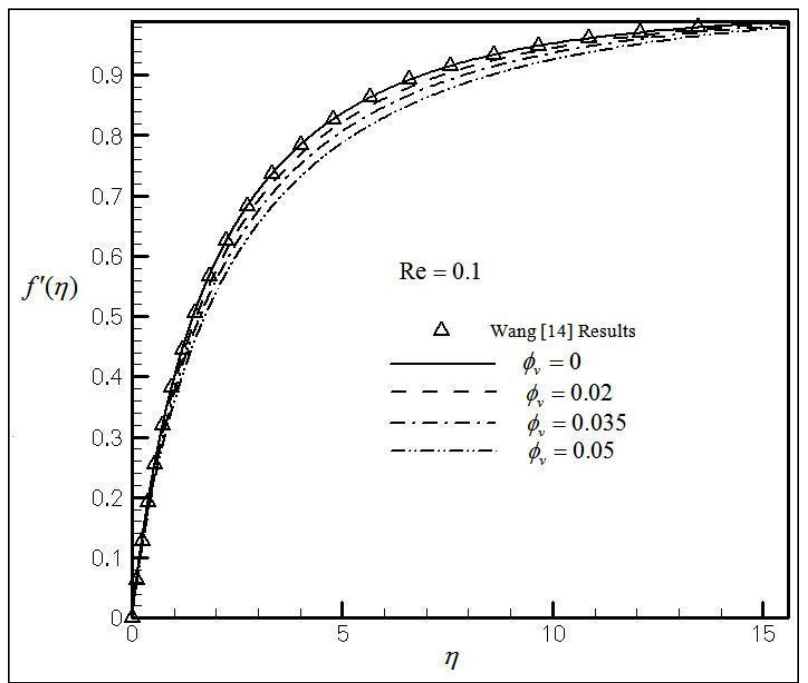

Fig. 9: Variation of $f^{\prime}$ in Terms of $\eta$ at $\operatorname{Re}=0.1$ and for Different Values of Particle Volume Fraction

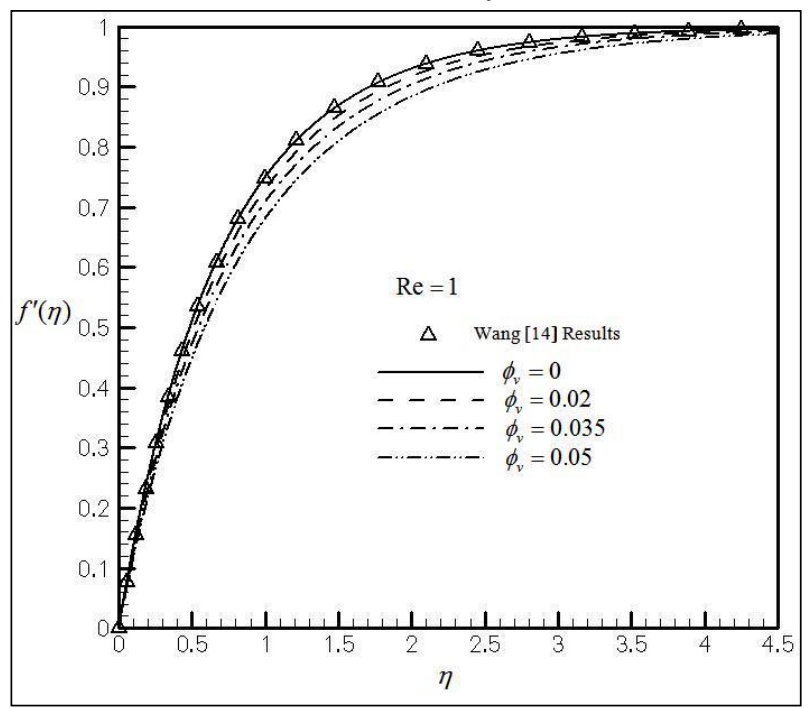

Fig. 10: Variation of $f^{\prime}$ in Terms of $\eta$ at $\operatorname{Re}=1.0$ and for Different Values of Particle Volume Fraction

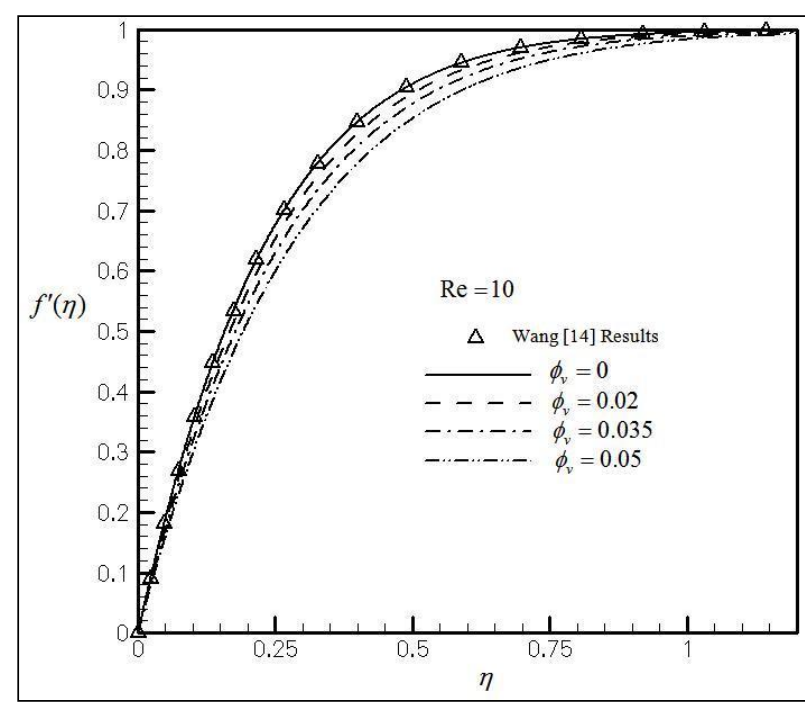

Fig. 11:Variation of $f^{\prime}$ in Terms of $\eta$ at $\operatorname{Re}=10$ and for Different Values of Particle Volume Fraction 


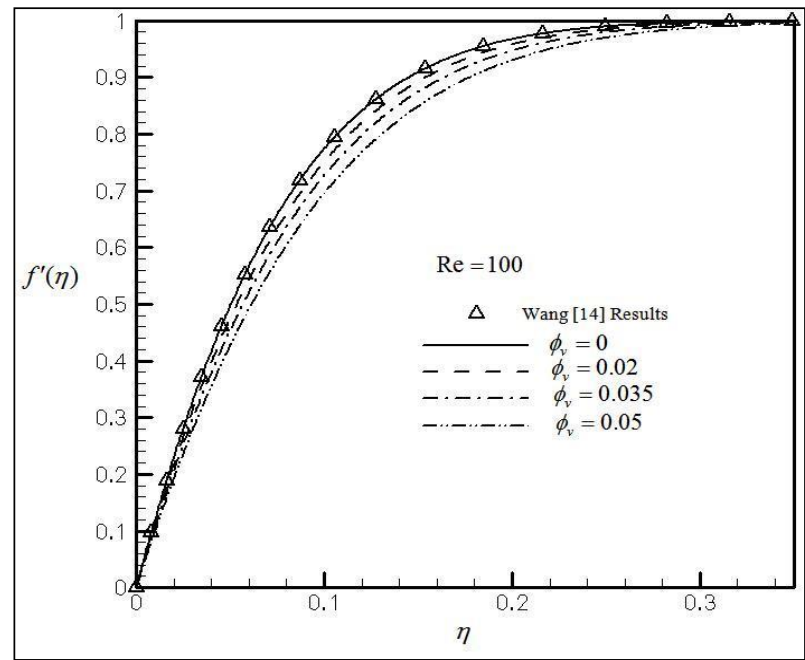

Fig. 12: Variation of $f^{\prime}$ in Terms of $\eta$ at $\operatorname{Re}=100$ and for Different Values of Particle Volume Fraction

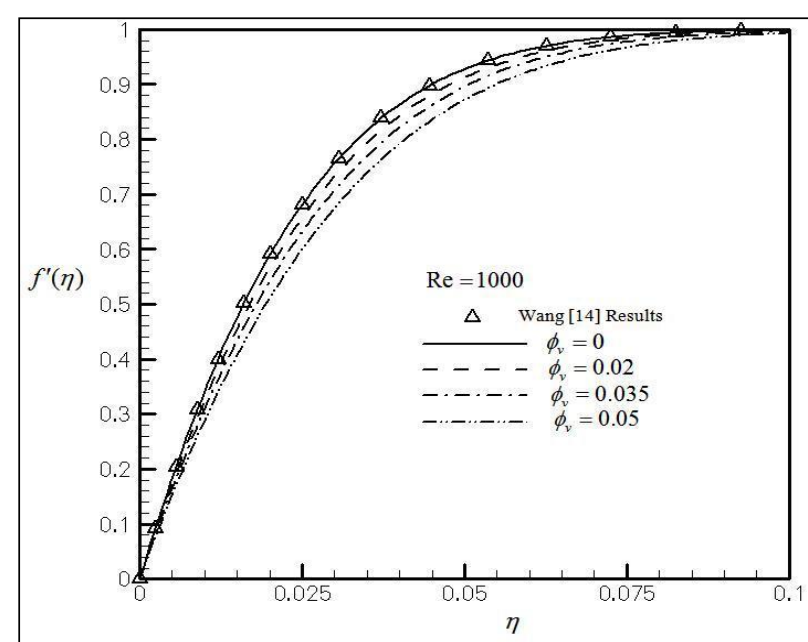

Fig. 13: Variation of $f^{\prime}$ in Terms of $\eta$ at $\operatorname{Re}=1000$ and for Different Values of Particle Volume Fraction

Sample profiles of pressure function against $\eta$ for the case of $\phi_{v}=0.02$, $\mathrm{z}=0$ and for selected values of Reynolds numbers are shown in Fig. 14. As expected, by an increase of Reynolds number the depth of diffusion of fluid pressure increases.

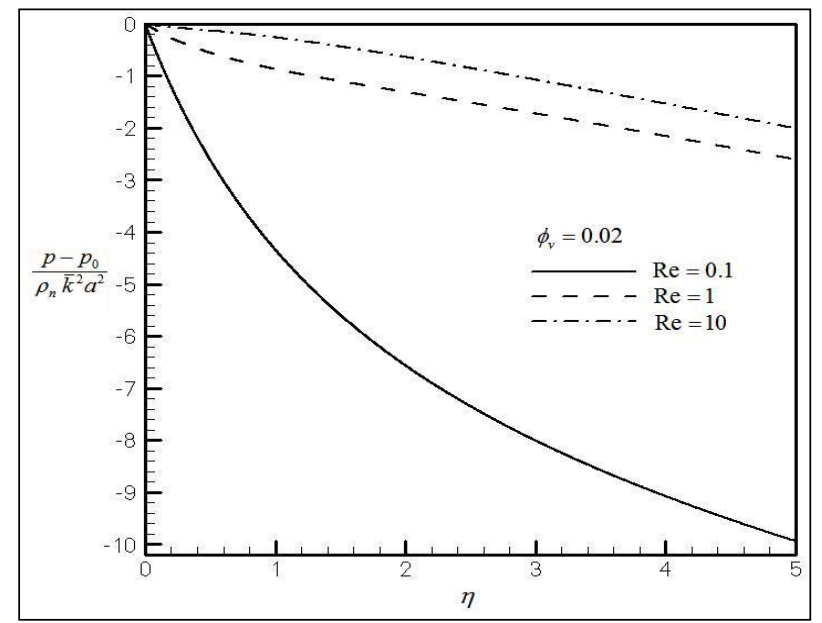

Fig. 14:Variation of Pressure Function in Terms of $\eta$ at $\phi_{v}=0.02$ and for Different Values of Reynolds Number.

Sample profiles of pressure function against $\boldsymbol{\eta}$ for particle Volume fraction factor for the case of $\mathrm{Re}=0.1, \mathrm{z}=0$ is presented in Fig.15. the largest amount of pressure is produced for the case of base fluid $\left(\phi_{v}=0\right)$. As $\phi_{v}$ increases, the pressure function decreases.

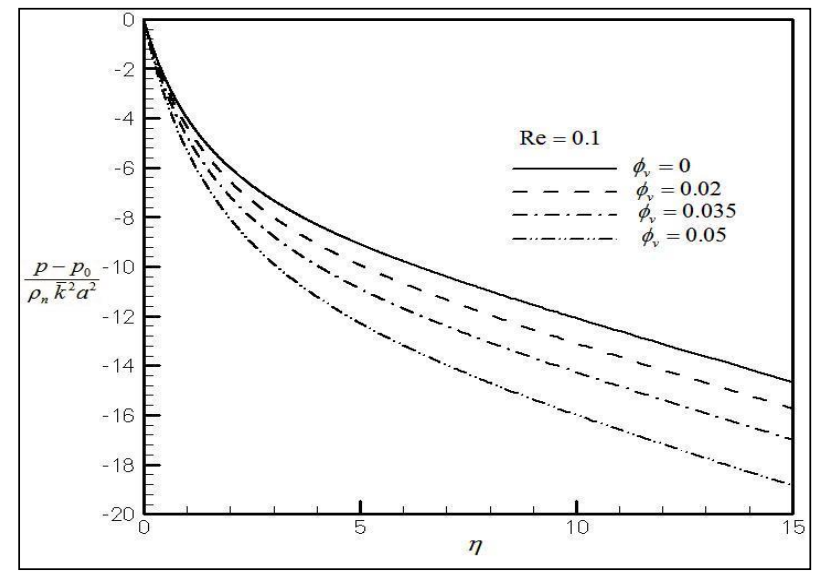

Fig. 15:Variation of Pressure Function in Terms of $\eta$ at, $\operatorname{Re}=0.1$ and for Different Values of Particle Volume Fraction 
It can be shown that the trend of above variations are the same for $\operatorname{Re}=1,10,100$ and 1000 .

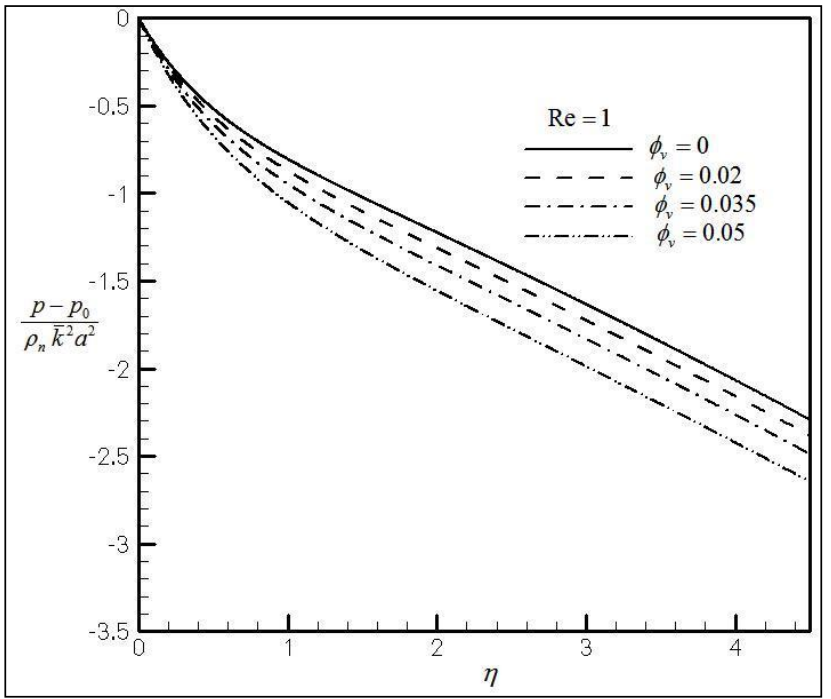

Fig. 16:Variation of Pressure Function in Terms of $\eta$ at $\mathrm{Re}=1.0$ and for Different Values of Particle Volume Fraction

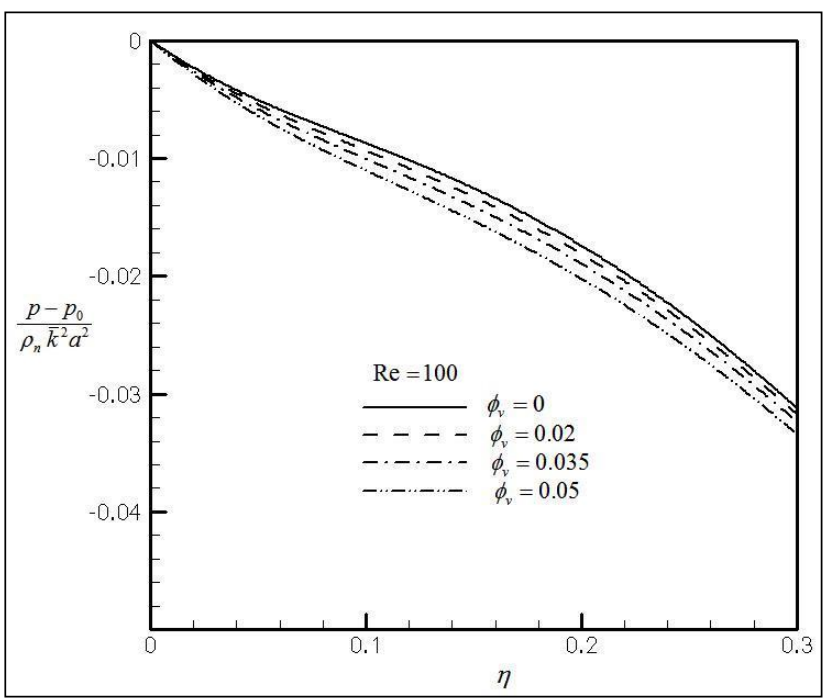

Fig.18: Variation of Pressure Function in Terms of $\eta$ at $\operatorname{Re}=100$ and for Different Values of Particle Volume Fraction

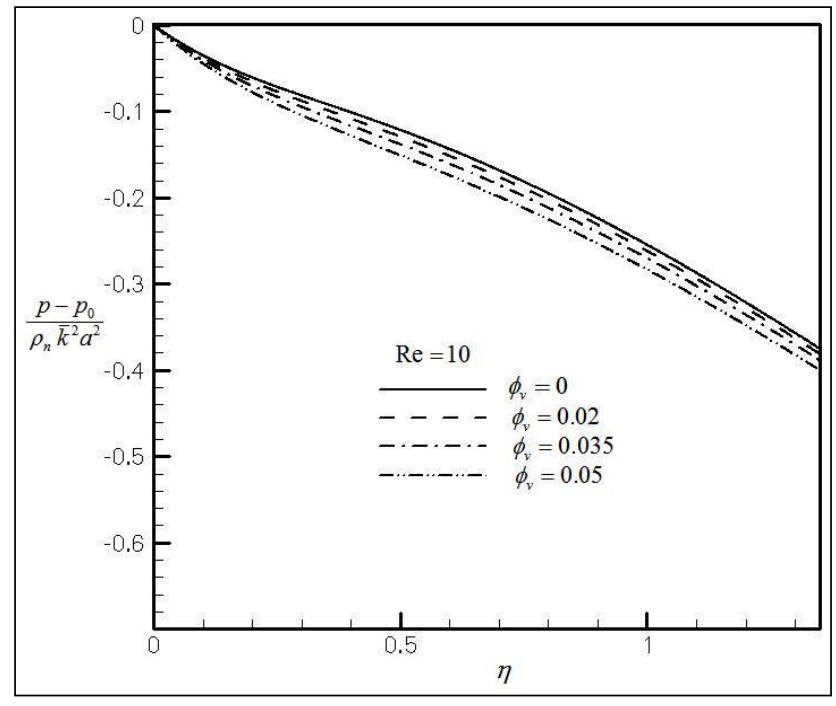

Fig. 17:Variation of Pressure Function in Terms of $\eta$ at $\operatorname{Re}=10$ and for Different Values of Particle Volume Fraction

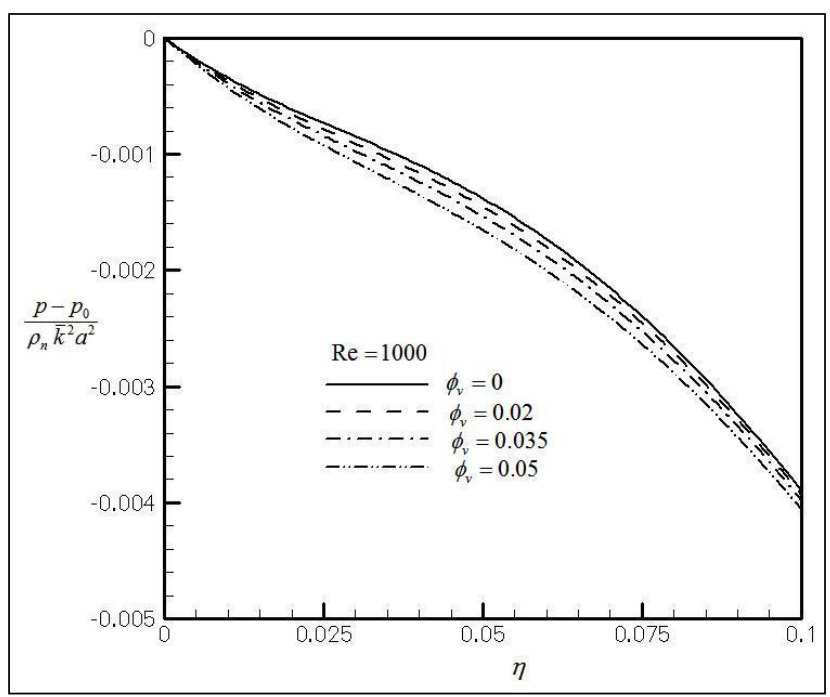

Fig. 19:Variation of Pressure Function in Terms of $\eta$ at $\operatorname{Re}=1000$ and for Different Values of Particle Volume Fraction

Sample profiles of surface shear-stress against Reynolds Number are shown in Fig. 20, for selected values of particle Volume fraction. As expected, as the particle Volume fraction increases the surface shear-stress decreases.

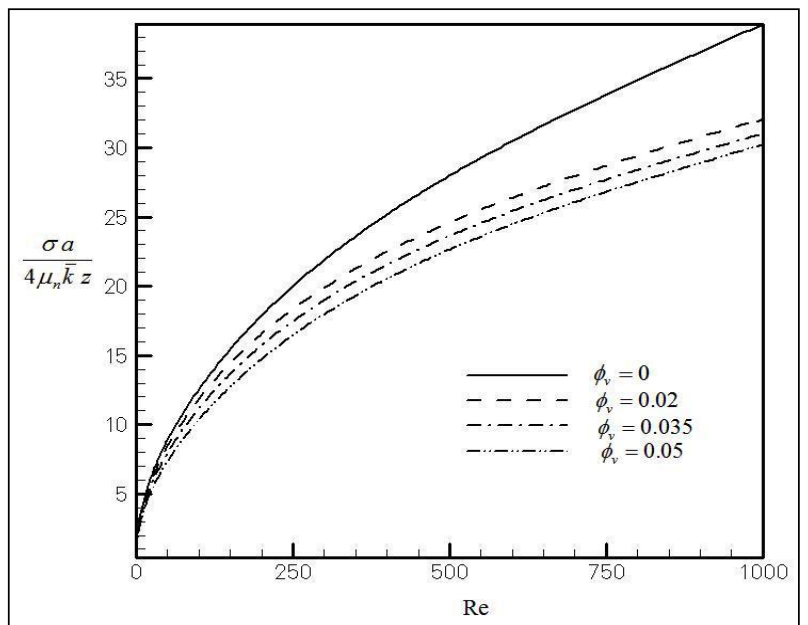

Fig. 20:Variation of Shear-Stress in Terms of Re and for Different Values of Particle Volume Fraction 
Sample profiles of surface shear-stress against particle Volume fraction are shown in Fig. 21, for selected values of Reynolds numbers. As expected, the more the Reynolds number the more is surface shear-stress.

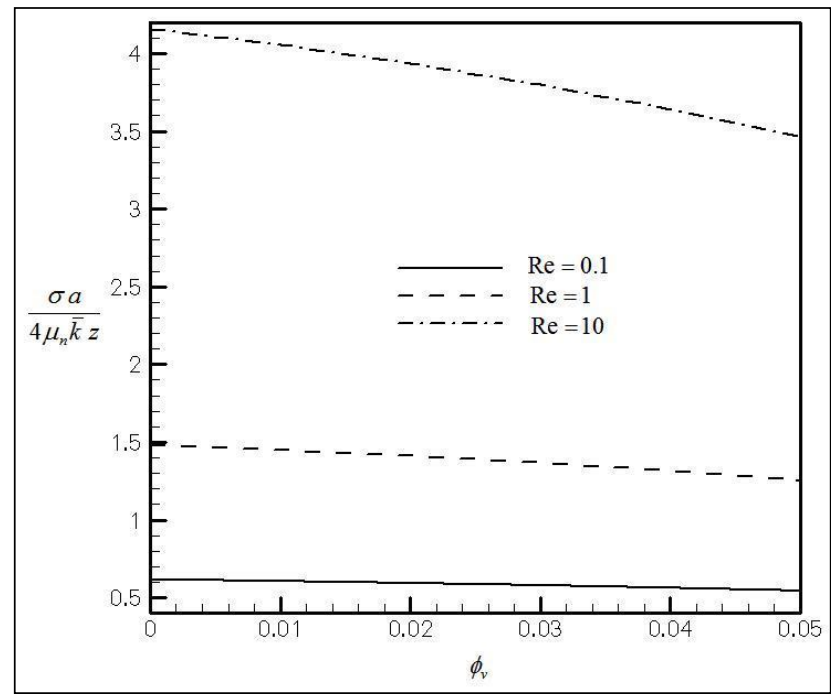

Fig. 21:Variation of Shear-Stress in Terms of $\phi_{v}$ and for Different Values of Reynolds Number

\section{Conclusion}

An exact solution for the Navier-Stokes equations has been obtained for the problem of axisymmetric stagnation-point flow of a nanofluid on a stationary cylinder. A reduction of these equations is obtained using appropriate transformations introduced for the first time. The general self-similar solution is obtained when the wall temperature of the cylinder is constant. All the solutions above have been presented for Reynolds numbers, ranging from 0.1 to 1000 and different values of particle volume fraction $\phi_{v}$. It can be said that for all Reynolds numbers, as $\phi_{v}$ increases the depth of diffusion of the fluid velocity field in radial direction, the depth of the diffusion of the fluid velocity field in $z$ direction, shear-stresses and pressure function decreases.

\section{References}

[1] S. U. S. Choi, Enhancing thermal conductivity of fluid with nanoparticles, Dev. Appl Non-Newtonian Flows. 66 (1995) 99 -105.

[2] S. E. B. Maiga, C.T. Nguyen, N. Galanis, G. Roy, Heat transfer behaviors of nanofluid in a uniformly heated tube, SuperlatticesMicrostruct. 35 (2004) 453-462.http://dx.doi.org/10.1016/j.spmi.2003.09.012.

[3] S. Z. Heris, S. Gh. Etemad, M. N. Esfahani, Experimental investigation of oxide nanofluid laminar forced flow convective heat transfer, Int. Comm. Heat Mass Transf. 33 (2006) 529-535.http://dx.doi.org/10.1016/j.icheatmasstransfer.2006.01.005.

[4] W. Duangthongsuk, S. Wongwises, Heat transfer enhancement and pressure drop characteristics of TiO2-water nanofluid in a double-tube counter flow heat exchangers, Int. J. Heat Mass Transf. 52 (2009) 2059-2067.http://dx.doi.org/10.1016/i.ijheatmasstransfer.2008.10.023.

[5] A. K. Santra, S. Sen, M. Chkroborty, Study of heat transfer due to laminar flow of copper-water nanofluid through two isothermally heated parallel plates, Int. J. Therm. Sci. 48 (2009) 391-400.http://dx.doi.org/10.1016/j.ijthermalsci.2008.10.004.

[6] C. T. Nguyen, N. Galanis, G. Polidori, S. Fohanno, C. V. Pota, A. L. Beche, An experimental study of con- fined and submerged impinging jet heat transfer using Al2O3-water nanofluid, Int. J. Therm. Sci. 48 (2009) 401-411.http://dx.doi.org/10.1016/j.ijthermalsci.2008.10.007.

[7] A. V. Kuznetsov and D. A. Nield, Natural convection boundary-layer flow of a nanofluid past a vertical plate, Int. J. Therm. Sci. 49 (2010) 243-247.http://dx.doi.org/10.1016/j.ijthermalsci.2009.07.015.

[8] A. V. Kuznetsov and D. A. Nield, Thermal instability in a porous medium layer saturated by a nanofluid: Brinkman model, Transp. Porous Med. 81 (2010) 409-422.http://dx.doi.org/10.1007/s11242-009-9413-2.

[9] W. A. Khan and I. Pop, Boundary-layer flow of a nanofluid past a stretching sheet, Int. J. Heat Mass Transfer. 53 (2010) 24772483.http://dx.doi.org/10.1016/j.ijheatmasstransfer.2010.01.032.

[10] K. Hiemenz, Die Grenzchicht an einem in den gleichformingenFlussigkeitsstromeingetauchtengeraden, Kreiszylinder. DinglersPolytech. J. 326 (1911) 321-410.

[11] F. Z. Homann, Der Einfluss grosser Zahighkeitbei der Strmung um den Zylinder und um die Kugel, Zeitsch. Angew. Math. Mech. 16 (1936) 153-164.http://dx.doi.org/10.1002/zamm.19360160304.

[12] L. Howarth, The boundary layer in three-dimensional flow, Part II. The flow near a stagnation point, Phil. Mag. Series 7. 42 (1951) 14331440.http://dx.doi.org/10.1080/14786445108560962.

[13] A. Davey, Boundary layer flow at a saddle point of attachment, J. Fluids Eng.10 (1951) 593-610.

[14] C. Wang, Axisymmetric stagnation flow on a cylinder, Quarterly of Applied Mathematics. 32 (1974) $207-213$.

[15] R. S. R. Gorla, Unsteady laminar axisymmetric stagnation flow over a circular cylinder, Dev. Mech. 9 (1977) $286-288$.

[16] R. S. R. Gorla, Nonsimilar axisymmetric stagnation flow on a moving cylinder, Int. J. Engineering Science. 16 (1978) $397-400$. http://dx.doi.org/10.1016/0020-7225(78)90029-0.

[17] R. S. R. Gorla, Transient response behavior of an axisymmetric stagnation flow on a circular cylinder due to time dependent free stream velocity, Int. J. Engng. Sci. 16 (1978) 493- 502. http://dx.doi.org/10.1016/0020-7225(78)90082-4. 
[18] R. S. R. Gorla, Unsteady viscous flow in the vicinity of an axisymmetric stagnation-point on a cylinder, Int. J. Engng. Sci. 17 (1979) 87-93. http://dx.doi.org/10.1016/0020-7225(79)90009-0.

[19] G. M. Cunning, A. M. J. Davis, Weidman, P.D., Radial stagnation flow on a rotating cylinder with uniform transpiration, J. Eng. Math. 33 (1998) 113-128. http://dx.doi.org/10.1023/A:1004243728777.

[20] H. S. Takhar, A. J. Chamkha, G. Nath, Unsteady axisymmetric stagnation-point flow of a viscous fluid on a cylinder, Int. J. Engng. Sci. 37 (1999) 1943-1957. http://dx.doi.org/10.1016/S0020-7225(99)00009-9.

[21] R. Saleh and A. B. Rahimi, Axisymmetric Stagnation-Point Flow and Heat Transfer of a Viscous Fluid on a Moving Cylinder with TimeDependent Axial Velocity and Uniform Transpiration, J. Fluids Eng. 126 (2004) 997-1005 http://dx.doi.org/10.1115/1.1845556.

[22] A. B. Rahimi and R. Saleh, Axisymmetric Stagnation-Point Flow and Heat Transfer of a Viscous Fluid on a Rotating Cylinder With TimeDependent Angular Velocity and Uniform Transpiration, J. Fluids Eng. 129 (2007) 107-115. http://dx.doi.org/10.1115/1.2375132.

[23] A. B. Rahimi and R. Saleh, Similarity Solution of Unaxisymmetric Heat Transfer in Stagnation-Point Flow on a Cylinder with Simultaneous Axial and Rotational Movements, J. Heat Transfer. 130 (2008) 054502.1-054502.5. http://dx.doi.org/10.1115/1.2885173.

[24] A. S. Abbasi and A. B. Rahimi, Non-Axisymmetric Three-Dimensional Stagnation-Point Flow and Heat Transfer on a Flat Plate, J. Fluids Eng. 131 (2009) 074501.1-074501.5.

[25] A. S. Abbasi and A. B. Rahimi, Three-Dimensional Stagnation- Point Flow and Heat Transfer on a Flat Plate with Transpiration, J. Thermophys Heat Transfer. 23 (2009) 513-521. http://dx.doi.org/10.2514/1.41529.

[26] A. S. Abbasi, A. B. Rahimi, H. Niazmand, Exact Solution of Three-Dimensional Unsteady Stagnation Flow on a Heated Plate, J. Thermophys Heat Transfer. 25 (2011) 55-58. http://dx.doi.org/10.2514/1.48702.

[27] A. S. Abbasi and A. B. Rahimi, Investigation of Two-Dimensional Stagnation-Point Flow and Heat Transfer Impinging on a Flat Plate, J. Heat Transfer, accepted as technical brief. (2011).

[28] S. V. Subhashini and G. Nath, Unsteady Compressible Flow in the Stagnation Region of Two-Dimensional and Axisymmetric Bodies, ActaMechanica. 134 (1999) 135-145. http://dx.doi.org/10.1007/BF01312652.

[29] M. Kumari and G. Nath, Unsteady Compressible 3-Dimensional Boundary Layer Flow near an Axisymmetric Stagnation Point with Mass Transfer, Int. J. Engineering Science. 18 (1980) 1285-1300. http://dx.doi.org/10.1016/0020-7225(80)90120-2.

[30] M. Kumari and G. Nath, Self-Similar Solution of Unsteady Compressible Three-Dimensional Stagnation-Point Boundary Layers, Journal of Applied Mathematics and Physics. 32 (1981).

[31] A. Katz, Transformations of the Compressible Boundary Layer Equations, SIAM Journal on Applied Mathematics. 22 (1972).

[32] N. Afzal and S. Ahmad, Effect of Suction and Injection on Self- Similar Solutions of Second-Order Boundary Layer Equations, Int. J. Heat Mass Transf. 18 (1975) 607-614. http://dx.doi.org/10.1016/0017-9310(75)90272-0.

[33] P. A. Libby, Heat and Mass Transfer at a General Three-Dimensional Stagnation Point, AIAA Journal, 5 (1967) 507-517. http://dx.doi.org/10.2514/3.4008.

[34] K. Gersten, H. D. Papenfuss, J. F. Gross, Influence of the Prandtl Number on Second-Order Heat Transfer Due to Surface Curvature at a Three-Dimensional Stagnation Point, Int. J. Heat Mass Transf. 21 (1978) 275-284. http://dx.doi.org/10.1016/0017-9310(78)90120-5.

[35] C. T. Nguyen, G. Roy, P. R. Lajoie, Refroidissement des microprocesseursa haute performance enutilisant des nanofluides. Congre`sFrancais de Thermique, SFT, Reims, 30 mai-2 juin (2005).

[36] M. Corcione, Empirical correlating equations for predicting the effective thermal conductivity and dynamic viscosity of nanofluids, Ene. Convers. Manage, 52 (2011) 789-793. http://dx.doi.org/10.1016/j.enconman.2010.06.072.

[37] W. H. Press, B. P. Flannery, S. A. Teukolsky, W. T. Vetterling, Numerical Recipes: The Art of Scientific Computing, Cambridge Univ. Press, New York, (1997) 548. 